\title{
O LEGADO GREGO NA TERMINOLOGIA GRAMATICAL BRASILEIRA
}

\author{
Maria Helena de Moura NEVES*
}

- RESUMO: Este estudo tem como objetivo pesquisar a existência de um legado grego terminológico na organização gramatical brasileira, considerando que a gramática incipiente grega é a fonte da nossa gramática, por via da gramática latina, e que o recorte de campo que ela preparou é um ponto de referência para o estudo da evolução do pensamento ocidental sobre a linguagem. A orientação teórico-metodológica se assenta na Linguística Histórica, na linha que orientou a ampla pesquisa sobre a emergência da gramática no Ocidente que constitui a fonte das informações que aqui se organizam (NEVES, 2005). As reflexões dirigem-se especialmente para o exame da nomenclatura, entendendo que ela mapeia conceptualmente o conjunto das posições assumidas, e em geral mantidas, que merecem apreciação. Entre outras coisas o exame opôs: termos gregos legados na corrente contínua do pensamento gramatical a termos gregos introduzidos posteriormente; termos transliterados do grego a termos decalcados da tradução latina. Além disso, verificaram-se casos de alteração de nome com manutenção de conceito, e casos de alteração de conceito para um nome conservado. De todo modo, o exame da nomenclatura revela a indiscutível existência de um legado grego à organização da gramática portuguesa.

- PALAVRAS-CHAVE: Nomenclatura gramatical brasileira. Gramática alexandrina. Gramática ocidental.

\section{Introdução}

É indiscutível a existência de um legado grego ao modo de organização da gramática portuguesa, como representante que é da gramática ocidental, oriunda da latina, que é calcada na grega. O histórico de constituição de uma terminologia gramatical é de significação notável na evolução do pensamento sobre a linguagem, tendo merecido atenção dos estudiosos pelo que representa de apreciação dos pressupostos e dos princípios que dirigiram e até hoje sustentam a instituição da disciplina "gramática" entre nós.

As reflexões que aqui se fazem enveredaram por um componente particular dessa herança na terminologia gramatical, entendendo que assim se mapeia

* UPM - Universidade Presbiteriana Mackenzie. Centro de Comunicação e Letras - Programa de Pós-Graduação em Letras. UNESP - Universidade Estadual Paulista Júlio de Mesquita Filho, Campus de Araraquara, Faculdade de Ciências e Letras, Departamento de Linguística - Araraquara - SP - Brasil. 14801-30 - mhmneves@uol.com. br. Pesquisadora do CNPq. 
conceptualmente o conjunto das posições assumidas, e em geral mantidas, que merecem apreciação. Tomando como universo de exame os termos constantes da vigente Nomenclatura Gramatical Brasileira ${ }^{1}$ (de agora em diante, NGB), este estudo procura verificar em que extensão e de que modo se conservam, na exposição gramatical oficial, os termos criados na gramática grega, implicada, aí, a verificação de correspondências com as escolhas terminológicas da gramática latina, sucedânea da grega.

O que aqui se traz é uma amostra, que é bastante abrangente mas não esgota a questão, e ficam necessariamente sem avaliação, dada a restrição de espaço, muitas implicações envolvidas, relacionadas, por exemplo, aos pressupostos filosóficos de base e ao consequente recorte de campo particular de cada conjunto.

\section{As fontes gregas}

A fonte principal das indicações que aqui se fazem é o estudo publicado no livro A vertente grega da gramática tradicional: uma visão do pensamento grego sobre a linguagem (NEVES, 2005), no qual, a partir de fontes diretas e de estudos precedentes sobre essas fontes, analiso e avalio a emergência da disciplina gramatical entre os gregos. Dado o fato de que o recurso a fontes foi muito extenso e muito particularizado para tantos fatos em estudo, deixo de indicar aqui, a cada momento, a fonte específica da informação, e também deixo de oferecer a bibliografia completa, ao final. Não há, portanto, remissão a fontes a cada fato de gramática informado, o que perturbaria a própria leitura do texto. Se necessário, qualquer indicação poderá ser localizada, com facilidade, no capítulo específico do livro fonte, no qual está também a lista completa das referências. As poucas citações de obras que aparecem no curso deste texto são feitas com remissão a esse livro. Apenas forneço, nas referências bibliográficas, ao final, as obras citadas que são as fontes diretas mais constantes: especialmente as edições de Dionísio o Trácio (séc. II-I a.C.) e de Apolônio Díscolo (primeira metade do séc. II d.C.), às quais também remetem algumas notas de rodapé.

Cabe observar, ainda, que as lições que se creditam a Dionísio o Trácio (de agora em diante, DT) representam, na verdade, referência a toda a Escola de Alexandria (séculos III e II a.C.), à qual ele pertencia. ${ }^{2}$ Sabe-se que o grande mestre da Escola, Aristarco da Samotrácia (215-145), apontado como autor de centenas

Para poder fixar-se em um determinado conjunto de nomenclatura proposto e evitar dispersão, este trabalho tem como referencial a Nomenclatura Gramatical Brasileira (NGB) oficial, que é a que rege as intervenções oficiais no setor. A Portaria e o texto da NGB foram publicados no Diário Oficial (da União), de 11/5/1959, Seção I, p. 11.088. O texto fonte está referenciado como Barbosa (1962).

2 Indique-se, ainda, que a autoria de seu manual tem sido contestada, fato que aqui fica fora de questão, por não pertinente quanto ao resgate de saber que interessa. 
de volumes de comentários e de tratados críticos, já reconhecia as mesmas oito "partes do discurso" (mére lógou) de DT. Entretanto, tudo o que Aristarco tenha escrito se perdeu, e dos outros gramáticos alexandrinos restam apenas fragmentos e informações vindas por referências indiretas. É a DT que se atribui uma Arte da gramática (Téchne grammatiké), a primeira gramática do Ocidente, que foi editada pela primeira vez em $1715,{ }^{3}$ e que representa a gramática alexandrina. Por sua vez, Apolônio Díscolo ${ }^{4}$ (de agora em diante, AD), da Escola de Pérgamo, deixou uma longa obra, mas a maior parte do que foi produzido não chegou até nós. São fontes do estudo da doutrina de $\mathrm{AD}$, além das quatro obras que restaram (Do pronome, Das conjunções, Dos advérbios, Da sintaxe das partes do discurso), todas elas consultadas para o estudo, os Escólios da Gramática de DT - onde a doutrina de $\mathrm{AD}$ se opõe à deste gramático - e a obra de Prisciano, que, comprovadamente, usou AD como modelo ${ }^{5}$. Essas fontes diretas - registre-se mais uma vez - são listadas nas referências finais.

\section{A direção de análise}

O exame empreendido verificou uma primeira distinção entre termos gregos trazidos na corrente contínua do pensamento gramatical e termos de formação grega introduzidos posteriormente. Outra bipartição verificada refere-se a termos transliterados diretamente do grego e termos oriundos da tradução latina da gramática grega. Por outro lado, o exame dos termos vigentes mostrou casos de alteração da denominação e manutenção do conceito (ou da aplicação), e, inversamente, casos de alteração do conceito (ou da aplicação) e manutenção da denominação.

Uma questão que se mostra de grande interesse e importância é a distribuição pelos diversos compartimentos da gramática desses diversos tipos de processamento histórico das denominações, o que se explicitará na exposição.

Na seção referente às "partes do discurso", foco de interesse dos filósofos, dentro de seu esforço de categorização e de estudo da proposição, estão muito presentes entre nós as denominações gregas, já que um compartimento desse tipo (embora desviado o foco de interesse) era votado a especial abrigo na organização

3 O estudo valeu-se especialmente da edição de G. Uhlig, Dionysii Thracis Ars grammatica, de 1883 e, ainda, da de I. Bekker, Anecdota graeca, de 1965. A edição de Bekker traz também numerosos escólios de escritores bizantinos, a que se tem de recorrer, para elucidação.

4 Consta que esse cognome (Dýscolos) tenha vindo do fato de sua linguagem não é elegante e, às vezes, é de difícil compreensão.

5 As obras supérstites de AD estão editadas por B. G. Teubner, em Grammatici graeci, 1867-1910 (APOLONIUS DISCOLUS, 1919), com aparato crítico e comentários de G. Uhlig ou G. Schneider. As obras Das conjunções e Dos advérbios estão editadas por I. Bekker, Anecdota graeca, 1965. Os textos de Prisciano estão em Grammatici latini, ed. H. Keil, 1961. (PRISCIANO, 1961). 
altamente taxonômica da gramática helenística. Uma indicação importante refere-se ao fato de que DT, na sua téchne grammatiké (§11), do primeiro século antes de Cristo, na linha de pensamento dos gramáticos alexandrinos, como já observei, já distingue oito partes do discurso, compondo um esquema com o qual o de nossas gramáticas tem bastante semelhança: nome (ónoma), verbo (rhêma), artigo (árthron), pronome (antonymía), preposição (próthesis), advérbio (epírrhema) e conjunção (sýndesmos), além de particípio (metoché), que hoje não está distinguido como uma classe à parte. ${ }^{6}$ Além disso, essa classificação de DT representa as reflexões filosóficas de muitos séculos, uma vez que várias das denominações já se registravam nos filósofos, como mostrarei.

Um compartimento à parte a que se deve fazer alusão, abrigado especialmente na Morfologia, constitui-se de termos novos (pouco numerosos), ligados a preocupações mais recentes de classificação, para os quais em geral a tradição prescindiu de filiação a uma formação grega, ou recorreu posteriormente a uma formação, na base de elementos gregos, pelo latim ou não. Eles serão tratados na parte final do texto.

\section{A origem das denominações abrigadas na Nomenclatura Gramatical Brasileira}

A primeira observação na análise das denominações das três grandes partes do documento, e que são as partes tradicionais da gramática - Fonética, Morfologia e Sintaxe -, é que elas têm formação grega, mas só sintaxe (sýntaxis) é termo ocorrente nos estudos filosóficos gregos sobre a linguagem (estoicos), embora não faltem considerações de cunho fonético já em Platão. Por outro lado, porém, dado o fato de que a "sintaxe" grega tinha total compromisso com a lógica, orientadora de toda a reflexão grega nessa área, é dentro desse terceiro compartimento da Nomenclatura oficial que está o menor número de termos gregos originais (apenas sujeito e predicado, vindos pela tradução latina). O próprio compartimento Sýntaxis não existe na gramática alexandrina incipiente, já ligada à crítica e à filologia, e sem a bênção direta da filosofia.

Na sequência se analisam as denominações constantes da NGB dos fatos e dos elementos que tenham vindo na tradição da gramática. A análise vai apresentando os termos segundo a seção da NGB em que estão inseridos. Como já indiquei, os termos que constituam denominações novas, ausentes da tradição gramatical, serão vistos em seção à parte. Também estarão em seção à parte os termos que não estão no corpo da NGB, mas se abrigam no Apêndice desse documento.

Em sentido contrário vai a indicação de que os gregos não distinguiam a classe interjeição (latim: interjectio, em Prisciano). 


\section{A primeira seção da NGB: a Fonética}

Como já apontei, o termo Fonética é ausente da gramática grega incipiente, o que não significa que se deixasse completamente sem tratamento essa área. Pelo contrário, dos cerca de cinquenta e cinco termos da NGB nesse compartimento (em geral, subclassificações de vogais e de consoantes, que os gregos ainda não faziam, o que naturalmente o exclui do nosso exame), onze são de herança da gramática grega. As considerações fonéticas dos gregos eram sobretudo vinculadas ao aspecto acústico, e os termos usados o revelam. Verifica-se que a tradição gramatical mantém uma classificação de base acústica, mas, na subclassificação, como mostrarei, mesclam-se critérios acústicos e articulatórios.

É por via da tradução que chegam ao português esses termos, já usados por Platão, Aristóteles e os gramáticos alexandrinos: vogais (já em Platão: tà phonéenta, "as que soam por si", "as vozes", ou tà phonémata grámmata, "as letras com voz"; latim: vocales; consoantes (em DT: tà sýmphona, "as que não são vozes, soando apenas quando combinadas com vozes"; latim: consonantes); semivogais (já em Platão: tà hemíphona, "as que são meio vozes", "as que não são vozes, mas têm ruído"7; latim: semivocales).

Outros seis termos da NGB abrigados na Fonética são transliterações do grego, ou seja, não passaram por tradução latina: ditongo (em DT: diphthongu, "som distinto", "voz"), referência feita apenas aos ditongos decrescentes; sílaba (em Platão, Aristóteles e gramáticos alexandrinos: syllabé, "reunião"; latim: syllaba), devendo-se observar que AD, quando admite a sílaba de apenas uma vogal, chama a isso "emprego abusivo", o que é consequência da consideração do significante a partir do elemento (até chegar ao lógos); oxítono (oxýtonos, "agudo"); paroxítono (paroxýtonos); proparoxítono (proparoxýtonos); ortoépia (em Platão: ortoépeia, "dicção correta"); prosódia (prosodía, termo frequente em Aristóteles, referindo-se a tudo o que serve para acentuar a expressão, como aspiração, acento prosódico, apóstrofo).

Merecem atenção especial, na NGB, o caso de fonema, que é termo já da ciência linguística e o caso de tritongo, empréstimo recente, analogicamente formado (ambos transliterados do grego). Tanto esses termos como o seu conceito estão ausentes, no registro do pensamento grego sobre a linguagem. O termo fonema introduziu-se, nos estudos linguísticos, como denominação

Como se vê, os elementos assim classificados não correspondem às que hoje se denominam semivogais: trata-se de consoantes, daquelas que não são "mudas" (já em Platão: áphona, "sem som"), aquelas que têm algum som, embora audível apenas quando se unem às vogais. Aristóteles fala disso referindo-se, por exemplo, às emissões de $\mathbf{s}$ e de $\mathbf{r}$, resultantes de uma aproximação de língua ou lábios. Isso faz a diferença entre as semivogais (determinadas consoantes que não são mudas) e as vogais, já que estas são audíveis sem que haja tal aproximação (Poética 20, 1456b 25-26; apud NEVES, 2005, p.137). 
da unidade mínima da Fonologia, e, portanto, com sentido já vinculado à teoria fonológica. ${ }^{8}$

Observo, por fim, que quase toda a terminologia que aparece no item relativo à tonicidade (tônica, átona, subtônica, etc.), embora abrigue palavras de formação grega, não transpõe nenhuma ordem de considerações que se possa entender como significativa na gramática grega, pois o que sobrelevava no exame dos elementos da cadeia falada era a quantidade vocálica e silábica, daí decorrendo a tonicidade.

\section{A segunda seção da NGB: a Morfologia}

Na NGB essa parte se divide em: a) estrutura e formação das palavras; b) flexões; c) classificação de palavras. No tratamento, do mesmo modo que ocorria no manual de DT, cada item vem seguido das flexões. Segue a análise, pela ordem da NGB.

\section{- Estrutura e Formação das PalaVRas}

Desse primeiro item, pouco se encontra na gramática incipiente grega.

Quanto à estrutura, apenas um termo da NGB lá está: tema, transliterado do grego (thêma, "o que é colocado", "o que é depositado"; na gramática, "forma primária"). ${ }^{9}$

Quanto à formação, acontece que a etimologia grega não reduziu a um sistema o processo de formação de palavras. AD chega a uma diferença entre radical e terminação, mas não tem um termo técnico para raiz ou radical. Ele sabe que as alterações não são caprichosas e desligadas, mas - pode-se verificar - não há entre os gregos uma preocupação de análise mórfica, pelo contrário, o movimento é o inverso.

Ainda nesse campo, também não se encontra na gramática grega uma apresentação que contemple os processos em si: derivação, composição ou hibridismo, relacionados na NGB. Por outro lado, semelhantemente ao que

\footnotetext{
Na gramática grega o que havia era stoicheîon ("elemento") e grâmma ("letra" / "som"). DT explica esses termos: grámmata, porque se moldam com caracteres, e stoicheîa, porque têm uma ordem e um lugar (NEVES, 2005, p.139), devendo-se registrar que este último termo se referia não apenas a "elementos" sonoros mas também a outros elementos da organização linguística. Quanto a grâmma, usado por Platão no Sofista (253a), onde a gramática vem como modelo para a dialética (já que a gramática é o sistema regulador da combinação das letras, assim como a dialética é o sistema regulador da combinação dos gêneros), cabe observar que o termo não tem, aí, o sentido etimológico de "símbolo gráfico", mas refere-se a som, pois Platão fala da possibilidade de concordância entre si, de união (ou não), dos grámmata. (NEVES, 2005, p.114)

9 Essa "forma primária", para o grego, é, por exemplo, o presente em relação ao futuro, ou é a palavra que serve para formar outra.
} 
ocorre nesse documento, as indicações de subclassificações do tipo de primitivo ou derivado se fazem, lá, dentro do estudo das diversas classes de palavras. E assim se fará na apresentação deste trabalho.

Exatamente por isso, a flexão das palavras, vista no geral (a consideração de palavras variáveis e palavras invariáveis, constitui uma verdadeira chave de entrada para a consideração dos termos e de sua subclassificação, na gramática grega incipiente. Se a filosofia se fixou nessa questão mais para verificar a existência de declinação (de ptôsis, "caso), que tinha grande importância na organização da proposição lógica, já nos estoicos se levantam quadros de flexão como paradigmas, e, paralelamente, levantam-se os desvios e irregularidades que o uso determinou. Os gramáticos gregos fixam-se fortemente na flexão de cada classe (distinguindo categorias "com" ou "sem" flexões), e apresentam um feixe das categorias gramaticais aplicáveis às diversas partes do discurso da língua grega, com isso organizando as formas em um sistema de flexão que fornece um padrão. Entretanto, quando a referência à flexão aparece nas definições das diversas classes, em geral o que está em questão é, mesmo, a flexão casual; por exemplo, verifica-se que, no advérbio, a definição registra explicitamente o termo ákliton que significa "sem flexões", "invariável", "não ligado à indicação de casos".

\section{- ClassificaÇão das palavras (e fleXÃo)}

Neste amplo compartimento, pode-se dizer que uma teoria das partes do discurso chegou a ser bastante completa e claramente construída na gramática grega. As denominações das classes vêm, no geral, por tradução latina, embora nem sempre haja correspondência exata de conceito ou de sua aplicação. É o que se pode dizer, muito especialmente, da denominação portuguesa substantivo (hypárktikos, "que subsiste por si", ligado a hýparxis, "existência"; latim: substantivus), termo que, na gramática grega, não designa classe de palavras. O termo grego que nomeia a classe correspondente a substantivo é ónoma, "nome", mas, de certo modo, a aplicação do termo é semelhante. Para Platão os nomes buscam imitar a essência das coisas (mímesis), e em DT, o tratamento da categoria nome recorre a ousía ("aquilo que é", a "essência"), enquanto AD fala em poiótes, "qualidade". Descartados os compromissos filosóficos, fica o substantivo (comum) como o nome que dá uma descrição daquilo que é nomeado. ${ }^{10}$

10 Em AD o conceito de nome refere-se à indicação da essência, mas por meio de uma qualidade comum ou particular, o que coloca o conceito de nome em relação complementar com o conceito de pronome, que apenas indica existência, como comentarei adiante. 
No caso do termo artigo (em Aristóteles, estoicos ${ }^{11}$ e gramáticos, árthron, "articulação"; latim: articulus, "articulação"), que é um elemento gramatical de que a língua latina não dispunha, vê-se que, no português, o conceito se altera e a aplicação se restringe. Em DT - portanto, já na gramática alexandrina - e também em $A D,{ }^{12}$ entre os artigos ficava não somente o artigo propriamente dito, referido como "(artigo) que se coloca antes" (árthron protaktikón), mas também o pronome relativo, referido como "(artigo) que se coloca depois" (árthron hypotaktikón). ${ }^{13}$ É o que mostro no estudo dos pronomes.

Mas na grande maioria dos casos de denominação das classes de palavras, como se vê a seguir, diferentemente do que ocorre com o termo artigo, a denominação se mantém (por tradução latina), e o conceito, ou a abrangência, se altera.

No caso do adjetivo (em DT: epítheton, "que é acrescentado", "que faz atribuição"; latim: adiectivum), há grande diferença na partição de campo dos diversos estudiosos. Em primeiro lugar, como mostrarei logo adiante, não se tratava de uma classe à parte, conforme demonstra o próprio modo de denominação encontrado, no qual epítheton vem como adjunto nominal: ónoma epítheton, nome adjetivo. Além disso, nem sempre os epítheta se incluíram entre os nomes. Inicialmente, pela possibilidade de os elementos assim denominados funcionarem como predicado, eles se incluíam entre os verbos (entre os rhémata, em Platão e Aristóteles), depois, sim, eles passaram a ser classificados como nomes. DT os incluiu entre as vinte e quatro espécies (eíde) nocionais dos nomes, e também $\mathrm{AD}$ os incluiu entre os vinte tipos de nomes que distinguiu.

No caso do numeral (arithmetikón; latim: numerale), do mesmo modo não se postulava uma classe à parte, como também mostrarei. DT e AD o colocaram entre as diferentes subclasses nocionais dos nomes, dando exemplos apenas de cardinais, que seriam os numerais por excelência. $\mathrm{O}$ (nome) ordinal (em

11 Os estoicos abrigavam inicialmente, entre os chamados artigos, alguns elementos pronominais, enquanto os pronomes pessoais ficavam entre os nomes comuns. Mais tarde, eles reconheceram a diferença entre a natureza do nome e a do pronome e colocaram os pronomes pessoais entre os artigos. Esta é a classificação que se resgata nos estoicos: a) (artigos) definidos (horisména), que são "definidos" em relação às pessoas gramaticais; trata-se dos pronomes pessoais e dos possessivos; b) (artigos) indefinidos (aoristóde), que são os artigos definidos e outros pronomes em geral, menos os possessivos e pessoais. Desses termos volto a falar quando tratar das denominações definido, indefinido e pessoal.

$12 \mathrm{AD}$ aponta que o próprio do artigo é a anáfora, ou seja, é referir-se a uma pessoa já determinada.

13 A consideração dos artigos definidos, juntamente com os pronomes relativos, entre os artigos (como artigo protático e artigo hipotático, respectivamente), deve-se ao fato de que AD considerava a "relação" (anaphorá) como a marca principal do artigo. Ele não desconhecia a diferença entre os dois tipos de entidade, pelo contrário, apontava distinção não apenas de forma e de colocação mas também de sintaxe (Da sintaxe 1, 142; apud NEVES, 2005, p.185). Essa diferença se refere especialmente ao fato de o artigo protático e o nome que ele acompanha formarem frase com o mesmo verbo, enquanto o hipotático requer outro verbo: o artigo hipotático liga-se ao nome pela "anáfora", mas relaciona-se com um verbo próprio, dessa relação dependendo o seu caso. 
DT e em AD: taktikón, "referente ao alinhamento"; latim: ordinale) é outra das subclasses.

No caso do pronome (em DT e em AD: antonymía, denominação que traz o prefixo anti, "no lugar de"; latim: pronomen, com o prefixo pro-, correspondente ao grego -anti $)^{14}$, o campo recoberto era bem diferente do que hoje se entende na organização da gramática. O manual de DT inclui entre os pronomes ${ }^{15}$ apenas aqueles que ele subclassifica como primitivo ${ }^{16} \mathrm{e}$ derivados, que são, respectivamente, os pessoais (prósopoil) e os que chamamos possessivos, os quais, entretanto, não recebem essa denominação, mas são chamados bipessoais (diprósopoi), porque encerram a ideia de possuidor e de possuído ${ }^{17}$. AD faz essa mesma classificação, mas alarga o domínio dos pronomes, não chegando a abrigar, entretanto, os nossos pronomes relativos, que, como já mostrei, ele deixa entre os "artigos antepostos". E, como mostrarei, ele põe como subclasses dos nomes as outras palavras que hoje se consideram pronomes ${ }^{18}$. Também mostrarei que, em DT, o termo relativo (anaphorikón, "de relação", "relativo","19 latim: relativum), era usado para designar uma subclasses dos nomes.

No caso da preposição (em DT e em AD: próthesis, "palavra que se coloca antes, em composição ou em construção"; latim: praepositio), a classe incluía os prefixos, e o significado do termo grego explica esse fato. ${ }^{20}$

14 Outras denominações vêm registradas como dadas por gramáticos ao pronome, segundo o depoimento de AD no Do pronome: paronomasía, "nome derivado" (Dionisodoro de Trezênia); semeíosis, "designação", "indicação" (Tiranião); antonomasía, que é outra forma de antonymía (Comano). (NEVES, 2005, p.166)

15 Segundo $\mathrm{AD}, \mathrm{DT}$ não distinguiu uma classe pronome, incluindo esse elemento entre os artigos, sob a rubrica de artigo demonstrativo (árthron deiktikón). Entretanto, no manual que chegou até nós há uma subclassificação entre artigo e pronome, que aqui registro. Essa referência de AD serve de argumento para muitos defenderem que o manual que possuímos não é de autoria de DT. Entretanto, essa não é questão para ser aqui discutida.

16 Como se percebe, o conceito das denominações primitivo e derivado referidas a pronome não corresponde ao conceito geral dessas denominações na nossa Nomenclatura.

17 Lembre-se que os casos de denominações da NGB que não têm ocorrência na gramática grega incipiente serão comentadas na parte final desta exposição, neste ponto elas são apenas indicadas.

18 A distinção que $\mathrm{AD}$ faz entre nomes e pronomes diz respeito ao fato de que o nome expressa a qualidade de um sujeito corpóreo, enquanto o pronome apenas faz indicação da coisa, apenas expressa a sua existência (Do pronome, p.31 e p.33; Da sintaxe I, 138; apud NEVES, 2005, p.187). Outra diferença que ele aponta refere-se ao fato de que o nome, ao contrário do pronome, só exprime a terceira pessoa, nunca podendo indicar nem o falante nem o ouvinte (Da sintaxe II, 43-47; apud NEVES, 2005, p.188). Para AD todo pronome é demonstrativo / dêitico (deiktiké) ou relativo / anafórico (anaphoriké); os de primeira e de segunda pessoa são sempre dêiticos; os de terceira pessoa são demonstrativos e relativos (Do pronome, p.10; Da sintaxe II, 8; II, 11; apud NEVES, 2005, p.189-190)

19 Essa subclasse recebia, ainda, as denominações: homoiomatikón, "de semelhança"; deíktikón, "demonstrativo"; antapodotikón, "de correspondência".

20 Para a preposição, $\mathrm{AD}$ já dá a importante lição de que, quando em posição livre, ela só se segue de nomes em caso oblíquo. 
No caso da conjunção (desde Aristóteles ${ }^{21}$ : sýndesmos; "união", "vínculo"; latim: coniunctio), inicialmente ficam abrangidas coisas muito diferentes (conjunções, preposições, pronomes). Com os estoico ${ }^{22}$ já não se incluem os pronomes, mas inclui-se tudo o que é indeclinável, com a definição feita pela função: ligar as outras partes do discurso. Esse é também o caráter acentuado em DT, que ainda insiste no valor de tal elemento na ordenação do pensamento. AD também faz indicação da "ordem' (táxis), mas põe a seu lado a "força" (dýnamis) o que poderia querer lembrar, já na definição, a subordinação ao lado da coordenação.

No caso do advérbio (nos estoicos, em DT e em AD: epírrhema, "ao lado do/sobre o verbo"; latim: adverbium), a denominação traz o mesmo prefixo epí ("sobre") que está em epítheton ${ }^{23}$, "adjetivo". Ou seja, o termo epírrhema é um correspondente do termo epitheton, no sentido de que epitheton está para "nome" assim como epírrhema está para "verbo" 24 . AD diz claramente que o advérbio é uma espécie de adjetivo do verbo, e deve vir após a preposição, que se liga ao nome. ${ }^{25}$

Resta observar o caso do termo verbo (nos filósofos e nos gramáticos: rhêma, "o que se diz", "predicado"; latim: verbum). Essa denominação grega e a denominação portuguesa verbo fazem conceituação análoga, mas não idêntica, já que a denominação de uma função (então vista a partir da lógica), como a de "predicado" representa um deslizamento de domínio, se tomada para denominar uma classe gramatical.

Saindo das denominações daquelas que hoje se consideram "classes de palavras", vamos a outras denominações, seja para subclassificação (principalmente na classe dos nomes, onómata), seja para flexão (principalmente na classe dos

${ }^{21}$ Cumpre observar que Aristóteles distingue esse elemento não como fato de gramática, ou mesmo como parte do lógos, mas como recurso de estilo, pela sua eficiência em fazer de muitas coisas uma unidade, ou seja, de, no discurso, fazer da multiplicidade uma unidade (Retórica III, 5 apud NEVES, 2005, p.148). O exame desse grupo, que abrangia um número muito maior de elementos do que o da nossa classe das conjunções, interessa-lhe, pois, mais como peça do discurso do que de proposições logicamente constituídas, ou seja, interessa-lhe mais como arte.

22 O exame das proposições não simples é muito importante na dialética estoica porque esta concerne às relações entre um fato que é objeto da percepção e um que não o é, ou seja, à determinação de um fato obscuro por meio de suas relações com um fato conhecido. Assim, a conceituação de conjunção (grupo que abrangia a conjunção, a preposição e outros elementos indeclináveis) tem ênfase no seu papel de conexão lógica (implicação, inferência, junção, disjunção, causa, comparação).

23 A denominação foi a vitoriosa entre outras, que se registram nos estoicos: mesótes, "intermédio"; pandéktes, "que abrange tudo". Segundo um escólio, a denominação mesótes se explica pelo fato de que os advérbios eram derivados justamente do caso que não distinguia o gênero em sua desinência, o genitivo plural. (BEKKER, 1965, p.939, 18-19, p.940, 6 apud NEVES, 2005, p.170).

24 AD registra, mesmo, epítheton rhématos, ou seja, "epíteto (adjetivo) do nome" (Da sintaxe, p.21, 17; apud NEVES, 2005, p.156).

25 Segundo um escólio, o advérbio assim visto indica poiótes, "qualidade" (BEKKER, 1965, p.939, 23-25, p.940, 2426 apud NEVES, 2005, p.170). 
verbos, rhémata). Verifica-se que, na denominação das subclassificações, bem como na das flexões, há uma maioria de traduções (geralmente latinas), cerca de trinta e cinco, nas quais em geral se mantém (em um sentido amplo) o conceito (muitas vezes mudando a aplicação do termo), e se altera a forma. A gramática grega incipiente não só classificou minuciosamente as partes do discurso como também desenvolveu bastante o estudo das flexões, uma característica da gramática emergente que deve ser destacada:

Quando examina as indicações de gênero, número, caso, tempo, modo, voz e pessoa (tà parepómena, "os acessórios"), aí, então, é que a gramática se move entre os fatos que poderíamos considerar mais especificamente gramaticais. Os filósofos naturalmente notaram esses fatos e teorizaram sobre eles, vinculando-os, sempre, porém, a um sistema filosófico. Notaram o geral, e apenas ocasionalmente, vendo aquilo que era evidente no exercício da linguagem, e sem um interesse específico. Os gramáticos, por sua vez, tinham de ter sua atenção despertada em particular para esses fatos, porque neles especialmente o criticismo encontrava as discrepâncias de uso em relação à linguagem dos poetas, e ainda porque eles facilmente se poderiam organizar em uma codificação empírica. Necessariamente essas indicações implicam entidades morfológicas, ou, mais ainda, morfossintáticas, e, assim, elas são as considerações formais ${ }^{26}$ por excelência no exame linguístico. Sua consideração leva forçosamente a uma caracterização e sistematização de formas. Assim, foi esse exame que mais diretamente instituiu paradigmas, o ponto básico da organização gramatical, nos moldes em que ela surgiu. Como nos outros aspectos, porém, o que a gramática pôs em um quadro prático, concreto e manipulável se apoiou na pesquisa espontânea e ocasional que estava disponível no material da filosofia. (NEVES, 2005, p.133-134).

Entretanto, às flexões o estudioso só pode chegar pelas subclassificações, e é o que aqui se faz. Os comentários se iniciam pelos termos introduzidos por tradução ou por transliteração das denominações gregas. A denominação por termos novos será vista mais adiante, uma discriminação que se justifica pelo fato de que o foco, neste estudo, é exatamente o modo, ou seja, o tipo de denominação.

A primeira indicação refere-se às duas espécies principais de nomes em DT: o (nome) primitivo (protótypon, "que é o primeiro"; latim: primitivum) e o (nome) derivado (parágogon, termo relacionado com o verbo parágo, "conduzir para outro lado", "derivar"; latim: derivatum), sendo os nomes derivados subclassificados, depois, em sete subespécies, como mostrarei mais adiante. Do mesmo modo, como já indiquei, em DT também os pronomes podem ser

26 Usa-se formal, aqui, no sentido tradicional, em oposição a nocional; opõe-se, então, forma a sentido. 
primitivos $^{27}$ (que são oS pessoais) e derivados (que são oS possessivos), denominações e conceituações que não são mantidas em nossa gramática. Cabe observar que, em princípio, a derivação não teria de ser considerada classe por classe, mas sim no geral das formas da língua, independentemente de sua categorização no sistema. Na verdade, a indicação, que também a NGB faz, de uma subclassificação em primitivo e derivado, separadamente, para as diversas classes $^{28}$, perde a oportunidade de considerar a formação das palavras como um processo independente de sua classificação.

Entre as sete subclasses de nomes derivados indicadas por DT, seis envolvem denominações que a NGB registra, ${ }^{29}$ muitas vezes com outras aplicações, como indicarei:

- (nome derivado) comparativo (em DT: synkritikón taktikós, ligado ao verbo synkríno, "reunir", "combinar", e, daí, "comparar"; latim: comparativum); trata-se de formas como andreióteros, "mais corajoso", portanto, trata-se dos (nomes) adjetivos em grau comparativo;

- (nome derivado) superlativo (em DT: hyperthetikón, ligado a hypérthesis, "ação de transpor"; latim: superlativum); trata-se de formas como oxýtatos, "agudíssimo", portanto, trata-se dos (nomes) adjetivos em grau superlativo;

- (nome derivado) diminutivo (em Aristóteles, tratando de retórica: hypokorismón; em DT, hypokoristikón, termo que se liga a koré, marca de ternura, de atenuação; latim: diminutivum); trata-se de formas como anthropískos, "homenzinho";

- (nome derivado) verbal (em DT: rhematikón; trata-se de formas como Filémon, derivada do verbo filéo; latim: verbale);

- (nome derivado) possessivo (em DT: ktetikón; latim: possessivum); trata-se de formas como Platonikón, "de Platão";

- (nome derivado) patronímico (em DT: patronymikón; latim: patronimicum); trata-se de formas como Peleídes, "filho de Peleu".

Como já indiquei, em geral as denominações subsistem na gramática com conceito similar, mas com aplicações bem diferentes, já que nem derivação nem expressão de grau levam, de fato, a uma subespecificação da classe dos substantivos. A denominação patronímico subsiste na NGB apenas como termo de gramática histórica.

Outra subcategorização grega para os nomes vai ao que DT indica, logo a seguir, como "figuras" (schémata), referindo-se à existência de um nome

27 Ver nota 17.

28 A NGB faz essa subclassificação para três delas: substantivos, adjetivos e verbos.

29 A outra subclasse traz uma denominação corrente nos estudos linguísticos, mas que a NGB não registra: parônimo 
"simples" (em DT: haploûn; latim: simplice), de um nome "composto" (em DT: sýntheton; latim: compositum) e de um nome "derivado do composto" (em DT: parassýntheton).

Além disso, nova grande subcategorização dos nomes é oferecida depois daquela primeira classificação que parte das grandes categorias primitivo e derivado. Agora, baseando-se em critérios mais nocionais, DT apresenta vine e quatro espécies bastante diversificadas de nomes ${ }^{30}$ As duas ordens de classificação que ele apresenta são paralelas, e uma não interfere na outra. Nessa nova relação, as denominações oscilam entre termos que sofreram tradução, termos que se transliteraram e termos novos (e que, portanto, são tratados neste texto $\left.{ }^{31}\right)$, e termos que foram completamente abandonados, ou não constam da NGB (e que, portanto, não vêm aqui comentados). ${ }^{32}$ Por outro lado, várias dessas denominações se referem, na nossa gramática, a outras classes que não a dos substantivos, e, assim, são comentadas em outros pontos deste trabalho. ${ }^{33}$

Uma das subclasses é a do (nome) demonstrativo (em DT e em AD: deíktikón; latim: demonstrativum), e o exemplos são tal e tanto (portanto, "pronomes", em nossa gramática). Outro subtipo é o (nome) indefinido (em DT e em AD: aóriston; latim: infinitum), cujo conceito não recobre o mesmo campo que o desse termo na nossa gramática: entre os exemplos de DT há relativos e correlativos, por exemplo o correspondente a qualquer que (ou seja, mais uma vez um "pronome" indefinido). Outro subtipo, ainda, é o (nome) interrogativo (em DT e em AD: erotematikón; peustikón; latim: interrogativum), cujos exemplos são quê? qual? (ou seja, o que denominamos pronome interrogativo).

Nessa relação, uma subclasse que claramente se abriga entre os substantivos, e que legou um termo para a nossa NGB é a do coletivo (em DT: periléptikon, "que pode ser abarcado", "que compreende em si"; latim: collectivum, "recolhido", ligado ao verbo colligo, "recolher"), com o exemplo povo. Trata-se, pois, de um caso em que a tradução latina não conserva exatamente a acepção do termo grego, embora a aplicação seja a mesma.

Acoplam-se às subclassificações as flexões do nome, na exposição gramatical dos gregos.

30 AD oferece vinte subclasses, coincidindo as indicações em dezessete casos. Subclasses que apenas estão em AD são pátrio, temporal e locativo, ausentes de nossas classificações.

31 Como subclasses dos nomes desse grupo, já foram tratados: adjetivo, numeral, ordinal. Serão tratados logo a seguir: demonstrativo / relativo, interrogativo, indefinido. Serão tratados mais no final do texto, na parte referente a denominações novas: próprio e comum.

32 Cito algumas das denominações dessas duas últimas categorias de "nomes": ferônimo, diônimo, epônimo, étnico, distributivo, compreensivo, onomatopaico, genérico, específico, absoluto, partitivo

33 Cito os termos: homônimo, sinônimo. 
DT e AD indicam os três tipos de gênero gramatical (génos; latim: genus) da língua grega, já nomeados desde os filósofos: masculino (árren, arrenikón / arsenikón, "macho", "do sexo masculino", "masculino"; latim: masculinum); feminino (thély, thelykón, "de mulher", "feminino"; latim: femininum); neutro (oudéteron, "nem um nem outro" ${ }^{44 ;}$ latim: neutrum), este último, um gênero gramatical inexistente na língua portuguesa. DT acrescenta os termos koinón, "comum" e epikoinón, "sobrecomum". Foi pelo entendimento do termo comum como "comum ao masculino e ao feminino" que se fixou a denominação "comum de dois", entretanto o sentido de "comum" explicitado nos escólios sobre DT é outro "o que tem a mesma declinação, mas se acompanha de diferentes artigos". O sentido de epikoinón também vem explicitado nesses escólios: "o que, com a mesma palavra, indica os dois gêneros, e, para essa indicação, recebe apenas um dos dois artigos, ou o masculino ou o feminino". Nossa Nomenclatura abriga, ainda, a transliteração do termo grego epikoinón, epiceno, que tem aplicação diferente, o que coloca o termo traduzido e o transliterado em distribuição complementar, dentro de uma determinada zona de acepção: o substantivo epiceno é aquele que é "sobrecomum" para animais, enquanto o sobrecomum se aplica a pessoas. Acrescente-se que, do mesmo modo que os gramáticos gregos, a NGB abriga esses cinco termos sob a rubrica Gênero.

DT e AD também nomeiam os três tipos de número (aríthmos, "quantidade de coisas contáveis"; "número") dos nomes da língua grega: singular (henikón, ligado à forma neutra hén do numeral "um"; latim: singulare); plural (plethyntikón, ligado ao verbo plethýno, "tornar numeroso", e aos substantivos plethýs, "multidão" e plethós, "grande quantidade"; latim: plurale); dual (dÿikón), este último, um número gramatical inexistente na língua portuguesa.

Quanto à subclassificação do pronome (antonymía), a indicação das espécies já se fez necessária, aqui, quando foi tratada a classe em geral, porque só assim se pôde diferenciar tal classe da classe do nome (ónoma).

Quanto aos chamados advérbios, há em DT uma ampla subdivisão (vinte e seis subclasses). As denominações gregas encontradas correspondem, na NGB, exceto no caso de interrogativo, a denominações feitas com expressões, e não, como no grego, feitas com adjetivos simples: (advérbio) de lugar (topikón, "relativo a lugar", "tópico"); de tempo (chrónou, "de tempo"); de negação ${ }^{35}$ (arnéseos,

34 Um escólio observa que alguns consideravam apenas dois gêneros, e define oudéteron pelo seu valor negativo (BEKKER, 1965 apud NEVES, 2005, p.199). Esse mesmo escólio indica que a diferença de gênero é apenas gramatical, não refletindo diferenças do mundo real. Com diferentes pontos de partida, Protágoras usa, para neutro, skeûos, "coisa", "artigo", e Aristóteles usa metaxý, "intermediário".

35 Há outra subclasse distinguida por DT que é complementar dessa, no campo em que estão hoje os nossos advérbios denominados como de negação, já que havia advérbios desse tipo (correspondentes ao nosso "não") diferentes, para diferentes tipos de sequências textuais. Enquanto essa subclasse dos advérbios de negação é exemplificada com a negação ou, "não" (usada, por exemplo, nas declarações, com indicativo), outra subclasse de advérbios semelhantes, denominados como de interdição (apogoreúseos), exemplifica-se 
"de denegação", ligado a árnesis, "ato de negar" e ao verbo arnéomai, "dizer que não", "desmentir"); apopháseos, "de recusa", ligado ao verbo apófemi, "dizer que não", "recusar"); de afirmação (synkatathéseos, "de assentimento")"36; de dúvida (eikasmoû, "de conjetura"); de intensidade ${ }^{37}$ (epitáseos, "de tensão", "de aumento de intensidade"), interrogativo (erotéseos, "de interrogação", ligado ao verbo erotáo, "inquirir", "interrogar", e ao substantivo erótesis, "interrogação", "questionamento"; latim: interrogativum). Os advérbios que denominamos como de modo correspondem a duas das subclasses de DT: os advérbios chamados de qualidade (poiótetos), como láx, "com o pé" (pýx), e os chamados de posição intermédia (mesótetos), que são os correspondentes aos nossos advérbios em mente.

Também os subgrupos das conjunções são muito especificamente indicados na gramática grega incipiente. Já havia uma cuidada subclassificação na filosofia, feita pelos estoicos, que distinguiram treze subespécies, com denominações grandemente ligadas à lógica e bastante discrepantes das nossas. Mesmo que a atenção seja posta nos gramáticos gregos, dificilmente relacionamos as denominações de nossas conjunções aos seus sýndesmoi, elementos sempre fortemente distinguidos pela sua importância no relacionamento lógico das proposições. DT distingue oito subclasses e AD, mais desligado do espírito alexandrino dos gramáticos e mais ligado à inspiração estoica, distingue dezenove subclasses. Apenas uma denominação que conservamos por tradução latina consta dessas três subclassificações gregas a que me refiro: é a denominação que corresponde ao nosso termo causal (latim: causalis), correspondente a dois termos gregos: aitiologikós, "que concerne à busca ou à indicação indicação das causas", "relativo às causas", "causal", denominação de DT e AD; aitiódes, "que contém a causa", "que exprime a ideia de causa", "causal", denominação dos estoicos e de $\mathrm{AD}^{38}$. Outras duas denominações que se encontram nessas subclassificações gregas correspondem a conceitos semelhantes aos de subespécies que a NGB registra, mas não traduzem os termos gregos: copulativas (symplektikoí, "que entrelaçam"), as nossas

com a negação mé, "não" (usada, por exemplo, nas proibições). Distinguia-se, ainda, o advérbio de negação por juramento (apomotikón) e de afirmação por juramento (katomotikón), exemplificados com partículas praticamente intraduzíveis.

36 Hoje incluem-se nessa classe os que DT denominava como de certeza (bebaióseos, "de confirmação", "de consolidação").

37 Nossos advérbios chamados de intensidade correspondem a esses (aí exemplificados com muito, fortemente), mas também correspondem aos que DT chamava de quantidade (posótetos), com o exemplo de muitas vezes (pollákis), e aos que ele chamava de comparação (synkríseos), com os exemplos de mais e menos.

38 Há dois termos em $\mathrm{AD}$ porque ele fazia, nesse campo, uma especificação mais miúda, considerando, dentro de uma classe que seria a das "causais" lato sensu (às quais ele dava o nome de aitiódes), as "causais propriamente ditas" (às quais a que ele dava o nome de aitiologikoî). 
$\operatorname{aditivas}^{39}$, com o exemplo e; disjuntivas (diazeuktikoí, "que disjungem", ligado ao verbo diazeúgnymi, "disjungir"), as nossas alternativas ${ }^{40}$, com o exemplo ou. Apenas mais um termo de AD corresponde a denominação nossa: adversativa (enantiomatikós, "que marca oposição"). Há, ainda, nos estoicos, em $\mathrm{DT}$ e em AD, uma denominação que é próxima da tradução latina de uma entidade apenas similar: conclusiva (prosleptikós, ligado ao verbo lambáno, que, na voz média, no campo da lógica, significa "ligar-se a", especialmente no sentido da ligação da premissa maior com a conclusão; latim: praesumptiva), por exemplo algumas partículas gregas correspondentes ao nosso ora.

A última classe de que aqui trato, com referência a subclassificações e/ou flexões, é o verbo (rhêma). É especialmente nessa classe que a existência de flexões constitui peça determinante da conceituação. AD insiste no fato de que, no caso do verbo, é uma mesma palavra que, alterando-se, adapta-se aos tempos, às pessoas e a todas as ideias que lhe são acessórias, enquanto o advérbio, que também pode indicar tempo, não o faz por mudança de forma. Desse modo, o que está em questão não é puramente o fato de a palavra fazer todas essas indicações, mas o fato de ser próprio dela essa alteração da forma para expressar as diferenças: especificamente, as diferenças de tempo e as diferenças entre atividade ou passividade (voz). ${ }^{41}$

Há, pois, grande número de termos designadores de subespecificações de formas verbais. O primeiro termo a comentar é conjugação (em DT e em AD: syzygía, "união sob o mesmo jugo"; latim: coniugatio). Por outro lado, esse termo designador de sistematização e exercitação metalinguística não era do interesse dos filósofos.

As lições gregas especificam o tempo verbal (chrónos; latim: tempus) considerando-o na sua ligação temporal com a elocução (exatamente a categoria linguística "tempo"), mas também incluem no exame das flexões verbais da língua grega muitas indicações que correspondem ao que denominamos, nos estudos linguísticos, como aspecto verbal. Já Aristóteles tratou do tempo nos verbos, observando distinções na forma verbal em correspondência com distinções na relação temporal com a elocução. Quanto aos estoicos, a sua preocupação peculiar de definir as relações de causalidade e os modos de conclusão lhes

39 No Anteprojeto da NGB (CHEDIAK, 1960), verifica-se que a comissão que elaborou o documento escolheu a denominação aditiva entre outras concorrentes, e uma delas era, exatamente, copulativa.

40 A comissão que elaborou a NGB escolheu a denominação alternativa entre outras concorrentes, e uma delas era, exatamente, disjuntiva (CHEDIAK, 1960).

${ }_{41}$ AD (Da sintaxe III, 51-59 apud NEVES, 2005, p.181) não considera como algo próprio do verbo nem a expressão do número nem a do modo, porque essas categorias pertencem às pessoas, bem como não considera que seja da natureza do verbo a indicação das pessoas. Assim, para $\mathrm{AD}$, se o que é particular ao verbo é expressar, por suas transformações, a diferença dos tempos e das vozes (e não das pessoas), o infinitivo está incluído entre os verbos, uma indicação que nem sempre foi feita na história da gramática grega (ver nota 53). 
proporcionou motivo para definir muito especialmente essas relações, e, por aí, levou à distinção quádrupla em dois tempos verbais considerados "determinados" (presente e passado), com dois valores aspectuais em cada um (durativo e completado). ${ }^{42}$ DT altera a classificação dos estoicos especialmente quanto à separação operada entre presente (que fica sem distinções aspectuais) e passado (que tem indicados quatro valores aspectuais), e quanto à inclusão do futuro. ${ }^{43}$ De $A D$ há a dizer que existem informações fragmentadas de sua doutrina sobre os tempos. A recolha geral da correspondência das denominações dos três tempos verbais de nossa NGB pode ser resumida como vem a seguir. Verificase uma correspondência com o quadro da gramática grega, tanto nos tempos como nas denominações: presente (em Aristóteles: he páronta; nos estoicos e em DT: enestós, particípio presente de enístemi, "estabelecer-se em”, "tomar consistência"; latim: praesens); pretérito (nos estoicos: paroichoménos, "que passou", particípio presente de paroíchomai, "ser passado", "ter transcorrido"; em DT: paralelytós, "que passou", particípio presente de parérchomai, "passar além", "transcorrer"; latim: praeteritum); futuro (nos estoicos e em DT: méllon, "que está por vir", particípio presente de méllo, "estar a ponto de", "estar para"; latim: futurum).

Também no caso do modo verbal (em DT e em AD: énklisis ${ }^{44}$ " "inclinação"; em AD, também diáthesis (tês psykhês), "disposição" (da alma); ${ }^{45}$ latim: modus), os filósofos não trabalharam com o conceito gramatical da categoria, prendendo-se ao valor lógico ou retórico das frases. ${ }^{46}$ Os gramáticos, por sua vez, assentaramse nas formas gramaticais, não nos tipos de frases, para a indicação dos modos. Nesse campo, nossa Nomenclatura gramatical abriga correspondência (exata

42 Combinam-se dois critérios, que correspondem ao que entendemos como tempo (presente e passado) e aspecto (durativo e completado). A bipartição segundo cada um desses critérios leva a uma divisão em quatro tipos, atribuindo-se a cada um deles um nome duplo: 1) enestós paratatikós ou atelés, "presente durativo", ou "imperfeito", que é o presente grego; 2) enestós syntelikós ou téleios, "presente completado", que é o perfeito grego; 3) paroicheménos paratatikós (ou atelés), que é o imperfeito grego; 4) paroicheménos syntelikós (ou téleios), que é o mais-que-perfeito grego. Esses eram os tempos determinados (horisménoi), mas havia os indeterminados (aóristol). Entre os indeterminados é que se alinha o futuro, ao lado do próprio aoristo grego.

43 A classificação tríplice de DT é a que segue: 1) enestós, que é o presente; 2) méllon, que é o futuro; 3) parelelythós, que é o passado, com os subtipos: paratatikós, "durativo", que é o imperfeito grego; paracheímenos, "completado", que é o perfeito grego; hypersyntélikos, "completado no passado", que é o mais-que-perfeito grego; aóristos, "indeterminado", que é o aoristo grego.

44 Observe-se que esse é o mesmo termo que designa a "flexão".

45 Por aí, o "modo" não precisaria referir-se unicamente ao verbo. AD aponta uma diferença entre uma énklisis optativa do verbo e uma do advérbio, com o exemplo eíthe, "oxalá" (Da sintaxe III, 95 apud NEVES, 2005, p.212).

46 Neves (2005, p.210-211) relaciona os seguintes tipos indicados por filósofos, com as fontes. Aristóteles: a ordem (entolé), o pedido (euché), a narração (diégesis), a ameaça (apeiIé), a interrogação (erótesis) e a resposta (apókrisis) (Poética, 19, 1456b). Protágoras, em Diógenes Laércio, IX, 53: a imprecação (eucholé), a interrogação (erótesis), a resposta (apókrisis) e a ordem (entolé). Estoicos, em Diógenes Laércio, IX, 66: a proposição, que é o fundamento da consideração, e da qual se distinguem: a questão, a interrogação, o imperativo, o juramento, a imprecação, a sugestão, o vocativo e o que é semelhante à proposição. 
ou não) com denominação grega nos casos do imperativo (prostaktiké, ligado ao verbo prostásso, "comandar"; latim: imperativus) e do subjuntivo (em DT e em AD: hypotaktiké, "posto sob" "que serve para limitar"; ligado ao verbo hypotásso, "subordinar", "sujeitar uma coisa a outra"; latim: subiunctivus). Outra correspondência que fica evidente é a do termo particípio, que, entretanto, como já mostrei, não se colocava entre os modos do verbo, mas constituía uma das oito classes gramaticais em DT e em AD (metoché, "participação", ligado ao verbo metéxo: "participar de"; latim: participium). As demais designações de flexões verbais vêm estudadas mais adiante, quando tratarei de denominações novas da NGB.

Quanto à voz verbal os estoicos fazem uma tripartição, que reflete o sistema grego de três vozes, mas que não tem base propriamente gramatical, dirigindo-se mais às predicações do que aos verbos. ${ }^{47}$ Os gramáticos, por sua vez, partem das alterações das formas verbais na expressão da voz, prendendose ao conceito de "disposição" (em DT e em AD: diáthesis; ${ }^{48}$ latim: vox), a qual é ativa (energetiké) ou passiva (pathetiké), desaparecendo o conceito de "neutro", para a categoria voz. As três vozes da língua grega se classificam, assim, em ativa (enérgeia, "força de ação"; latim: activa), passiva (páthos, "aquilo que se experimenta"; latim: passiva) e média (mesótes, "o que está no meio", inexistente na língua latina), com correspondência absoluta dos dois primeiros termos com aqueles que nomeiam as duas vozes da língua portuguesa. ${ }^{49}$

Ainda nesta seção dedicada às classes de palavras, suas subclassificações e flexões, chega-se a um compartimento de termos da nossa NGB que devem ser destacados como diferentes, tanto na forma como no conceito, das designações dadas pelas primeiras gramáticas gregas.

Novamente se começa pela classe do nome (ónoma), tão ampla e diversificada nas propostas originárias. Destacam-se os termos próprio (em DT e em AD: kýrion, "aplicado a uma pessoa"; latim: proprium) e comum (em DT e em AD: prosegorikón, "que serve para chamar ou saudar", "que nomeia", "apelativo"; latim: "commune"); prosegoría, "nome apelativo"50. Em grego, chama-se, pois,

47 Os predicados (kategorémata) são classificados em ativos (orthá, "retos"), passivos (hýptia, "supinos") e neutros (oudétera, "nem um nem outro").

48 A transliteração desse termo, diátese, é corrente nos estudos linguísticos, mas não é abrigada na NGB.

49 Entretanto, não se deve esquecer que a voz, em português, não representa, como representava no grego, correspondência com flexão verbal.

50 Apesar da denominação, Prisciano atribui a AD a definição segundo a qual o nome é a parte do discurso que mostra a qualidade própria ou comum do sujeito corpóreo ou incorpóreo: "Secundum Apollonium (nomen est) pars orationis quae singularum corporalium rerum vel incorporalium sibi subiectarum qualitatem propriam vel communem manifestat" (Part. XII vers. Aen. V, 95 apud NEVES, 2005, p.174). Assim, de todo modo, nossas denominações são caudatárias do pensamento grego sobre a linguagem. 
"apelativo" ao nome que verdadeiramente nomeia, ao nome "por natureza", já que o nome próprio se institui necessariamente "por convenção", posição que bem lembra a querela filosófica entre analogia e anomalia, e que não está refletida exatamente nos termos portugueses (e latinos).

Na classe dos pronomes merece novo comentário o termo possessivo (já no latim: possessivum) com que denominamos aqueles que os gramáticos gregos denominavam parágogoi, "derivados" (termo ligado a forma), ou diprósopoi, "bipessoais" (termo ligado a função), denominações que não carregam a noção de "posse", e que são muito bem aplicadas.

Outros casos de denominações diferentes em relação ao grego estão no campo dos modos verbais, outro setor de grande ligação com o pensamento filosófico, nos estudos gregos. Não corresponde à designação grega (e é fiel à denominação latina) o termo indicativo (em DT e em AD: horistiké, "que serve para delimitar", "definitório"; ligado a horismós, "definição"; latim: indicativus). ${ }^{51} \mathrm{Um}$ pouco diferente é o caso do termo infinitivo, de base latina mas não exatamente correspondente à tradução latina do grego (em DT e em AD: aparemphatikós / aparémphatos "indefinido (quanto a pessoa, número e modo)"; ligado ao verbo paremphaíno, "fazer ver", "pôr em evidência", "reproduzir (uma imagem)"; latim: infinitus), considerado um dos cinco modos verbais pela maioria dos gramáticos gregos. ${ }^{52}$

Quanto à denominação dos tempos verbais, em vários casos mudam os nomes e muda também a aplicação do conceito. Lembre-se, especialmente, que termos com imperfeito, perfeito e mais-que-perfeito, que hoje se indicam como denominações de "tempos", aparecem com denominação e também conceituação ligada mais a aspecto, na gramática grega, que mostra uma sensível compreensão das duas categorias, uma distinção metodológica que é facilitada pelo modo de expressão flexional dos verbos gregos: imperfeito (em DT e em AD: paratátikós, "que continua incompleto"; latim: imperfectum); perfeito (em DT e em AD: parakeímenos, "colocado lado a lado", daí, "que está presente"; latim: perfectum); mais-que-perfeito (em DT e em AD: hypersyntélikos, "completado no passado"; latim: plus quam perfectum); . Dos três, o termo grego correspondente

51 Fica sem indicação, por não termos esse modo verbal em nossa sistematização, o optativo (euktiké).

52 Seguindo a opinião dos estoicos, $\mathrm{AD}$ via no infinitivo a própria essência do verbo, e encontrava nele a ideia verbal em toda a sua pureza: o infinitivo é o verbo por excelência, é a forma mais geral (genikotáte) do verbo (Da sintaxe III, 58-60 apud NEVES, 2005, p.182). Para AD, como o verbo só representa as pessoas e os números quando exprime as disposições de alma, e como o infinitivo não representa nenhum movimento da alma, ele não representa pessoas nem números (BEKKER, 1965, p.883, 1-7 apud NEVES, 2005, p.182). Portanto, oS infinitivos se incluem entre os verbos, já que eles são precisamente as formas que não exprimem os estados de alma e não distinguem as pessoas (BEKKER, 1965, p.883, 7-13, apud NEVES, 2005, p.182). O gramático alexandrino Trifão (século I a. C.), pelo contrário, fundamentando-se no caráter abstrato do infinitivo e no fato de que ele pode assumir o papel de um substantivo quando precedido de artigo, não o admitia entre os modos do verbo e lhe chamava ónoma rhématos, "nome verbal". (EGGER, 1854, p.150 apud NEVES, 2005, p.181). 
a "imperfeito" é o que está mais próximo da conceituação do tempo verbal assim denominado em português.

Entre os termos relativos às vozes verbais, merece menção, nesta seção, a aplicação do termo reflexivo (em DT e em AD: antipeponthóta, "inverso", "recíproco", ligado ao verbo antipáscho, "sofrer em troca", "experimentar igualmente"), hoje destacado da noção de reciprocidade.

Finalmente, chega-se à consideração de termos totalmente novos, que, no geral, correspondem a seções ou a entidades da gramática que, como já observei em parte mais inicial deste texto, não mereceram interesse na gramática emergente, ou ainda não poderiam ter sido tratadas, no ponto de evolução do pensamento gramatical em que se instituiu a gramática no Ocidente. São, por exemplo, denominações desse elenco, na NGB (apresentadas pela ordem): morfologia; (nome) concreto, abstrato; ${ }^{53}$ coordenativa, coordenação; subordinativa, subordinação; (numeral) multiplicativo, fracionário; sintaxe, e todos os termos ligado a esse componente da gramática, exceto sujeito e predicado, que são termos traduzidos: sujeito (hypokeímenon); predicado (rhêma).

\section{A terceira seção da NGB: o Apêndice}

Pode-se dizer que o Apêndice da NGB é o "fecho grego" do documento. Entretanto, poucos dos termos vieram por uma tradição de estudos gramaticais, o que se revela, mesmo, no fato de eles serem, em grande parte (trinta, em setenta e sete) transliterações, e não traduções provindas do latim, o que os retira de um curso na história das ideias gramaticais.

Comecemos pelas Figuras de sintaxe, que têm todas as quatro denominações constituídas por transliterações do grego: anacoluto (anakoloúthos, "que não é a sequência de", "inconsequente"); elipse (elleípsis, "falta", "insuficiência"; oposto a hyperbolé; ligado ao verbo elleípo, "deixar atrás de si", "deixar de lado"); pleonasmo (pleonasmós, "excesso", "abundância", ligado ao verbo pleonázo, "ser excessivo"); silepse (sýllepsis, "ação de abarcar", "compreensão", termo encontrado em DT para falar de advérbios que têm ideia de reunião). O mesmo ocorre com os Vícios de linguagem, com todas as quatro denominações constituídas por transliterações do grego: barbarismo (barbarismós, já em Aristóteles: "uso de uma língua estranha"; em AD, "incorreção no uso da palavra, por ser estranha ao helênico"); solecismo (soloikismós, já em Aristóteles: "falta contra as regras da língua"; em AD, "incorreção na construção da frase"); ${ }^{54}$ cacofonia (em AD, kakophonía: "voz desagradável").

\footnotetext{
53 Lembre-se que a gramática grega sugeriu a distinção, mas não cunhou os termos.

54 Sóloi era colônia ateniense (na Cilícia), onde se falava mal.
} 
Continuemos com os termos de Gramática histórica (trinta e quatro), muitos deles formados no português (como ditongação, vocalismo, vocalização), com treze transliterações, mantendo-se ou o conceito e/ou a aplicação.

Nos casos seguintes não há uma idêntica aplicação de conceito: analogia (analogía), denominação que na NGB entra como questão de gramática histórica, e na história do pensamento linguístico grego entra na controvérsia filosófica de analogia versus anomalia; etimologia (etymología, "sentido verdadeiro ou primitivo de uma palavra"), que na nossa visão é uma questão técnica (gramática histórica), e no pensamento grego tinha profundas implicações filosóficas; crase (krâsis; sentido ativo: "mistura", "ação de misturar", oposto a mîxis, "mistura em que as coisas continuam distintas (grãos)"; sentido passivo: "mistura", "resultado de mistura"), termo de grande significação na filosofia, hoje questão formal e de aplicação sintática.

Em alguns casos, a correspondência de conceito é bastante próxima, embora sem geral a apreciação dos fatos denominados tenha diferentes direções: aférese (aphaíresis, "retirada"; em AD, "queda de uma letra"); apócope (apokopé, "amputação", ligado ao verbo apokópto, "golpear", "cortar"; em AD, "supressão de letras no final das palavras"); epêntese (epénthesis, "intercalação", ligado ao verbo epentithemi, "intercalar"); haplologia (haploûs, "simples" + lógos); hiperbibasmo (hyperbibasmós, "transposição", ligado ao verbo hyperbibázo, "fazer passar para outro lado"); metátese (metáthesis, "transporte", "transposição"); neologismo (néos + lógos); prótese (próthesis, "adição"); paragoge (paragogé, "ação de trazer", "ação de puxar"; verbo parágo, "conduzir de lado"; em AD, "derivação"); prótese (próthesis, "adição"), termo que, nos gramáticos, também denomina a classe das preposições); síncope (synkopé, "fracionamento em pequenos pedaços"; em AD, "supressão de letras").

Vamos à Ortografia (dezoito termos), que tem oito denominações ligadas ao grego, entretanto com apenas duas que são representativas de transliteração de termos constantes nas primeiras reflexões gramaticais gregas: homófono (homóphonos, "que fala a mesma língua", "que tem o mesmo som"; exemplo: nominativo e vocativo); apóstrofo (apósthrophos, "que se desvia", "de que alguém se desvia", ocorrente nos escólios de DT e em AD indicando elisão de vogal final). Três outras (alfabeto, dígrafo, homógrafo) têm formação com elementos gregos, mas não representam preocupações terminológicas da tradição grega..$^{55}$ O termo trema, embora transliteração do grego (trema, "furo", "buraco", "pontos sobre um dado", ligado ao verbo tetraíno, "furar", "cortar"), também não era ocorrente como termo da gramática.

55 Alphabetum, ressalve-se, está em Prisciano. 
Na parte referente à Pontuação (treze termos), apenas um constitui transliteração de termo grego constante dos estudos sobre língua e linguagem: ${ }^{56}$ asterisco (asterískos, "pequena estrela"), designação do sinal em forma de estrela com que os críticos marcavam as passagens de texto consideradas espúrias, e que também era usado como sinal de métrica. Por outro lado, designações novas, nesse compartimento, são ponto e vírgula, correspondente ao grego mése stigmé, "meio ponto", e vírgula, correspondente ao grego hypostigmé (literalmente: "subponto").

No setor da Significação das palavras, dois termos (que, na verdade se referem a subclasses de nomes, na gramática grega, e que, portanto, têm outra aplicação na NGB) vêm por transliteração: homônimo (homónymos, "que tem o mesmo nome") e sinônimo (synónymos, "que tem o mesmo sentido"). São dois termos muito importantes na visão aristotélica da relação entre as palavras e as coisas, ou seja, no tratamento da significação.

O Apêndice da NGB também traz denominações (cinco) que constituem tradução de denominações gregas. Termos da Ortografia são: acento (tónos, ligado ao verbo teíno, "estender"; latim: accentus); agudo (oxýs, "agudo"; latim: acutus); grave (barýs, "pesado"; latim: gravis); circunflexo (perispómenos, ligado ao verbo perispáo, "fazer uma conversão à direita ou à esquerda", "fazer obliquar duas vezes"; latim: circumflexus. Desse mesmo tipo é o termo de Pontuação denominado ponto final (stigmés7 ou teleía stigmé, "ponto (final)", com o adjetivo: téleios, "último", "final").

Ao final chegamos a preocupações novas de denominação, resultantes de direções que o campo de estudo tomou, e que são pouco numerosas. Como já apontei no início, esses termos são notados especialmente na Morfologia, e principalmente na parte referente à estrutura e formação de palavras. Muitas apresentam formação vernácula ligada ao grego, outras representam tradução latina. Citem-se, além de todas as denominações ligadas à classificação das vogais e consoantes: analítico / sintético; regular / irregular; (verbo) defectivo, abundante, auxiliar; monossílabo, dissílabo, etc.; tônico, átono, rizotônico, etc.; raiz, radical afixo, prefixo, sufixo, desinência, vogal temática, vogal de ligação, cognato, derivação, composição, hibridismo.

56 Os termos gregos para tal fim instituídos aparecem com os primeiros gramáticos alexandrinos. Aristófanes de Bizâncio (257-180) reduziu a acentuação e a pontuação a um sistema definido (SANDYS, 1915, p.38 apud NEVES, 2005, p.119-120). O universo de consideração era o da crítica filológica, especialmente a recensão de textos.

57 O termo grego stigmé, "estigma" designava sinal para marcar suspeita de condição espúria de uma palavra. 


\section{Considerações finais}

Como peça que é do conjunto ocidental da consolidação de uma visão sistematizada da gramática da língua, a organização da gramática vigente no Brasil é tributária, por via da gramática latina, da organização gramatical que emergiu do esforço de preservação da língua dos estudiosos de Alexandria, que, nas suas formulações, amparavam-se no aparato herdado do pensamento filosófico grego. Consequentemente, essa organização é tributária também da terminologia referente às entidades envolvidas.

Apesar de todos os novos encaminhamentos que a ciência linguística deu à visão e ao estudo da linguagem e da língua, em todo o Ocidente as organizações oficialmente instituídas conservam um núcleo comum bastante fixo do conjunto de termos que designam unidades, categorias e funções ligadas ao funcionamento das diversas línguas dessas nações. No português do Brasil, há um documento em que se registra a nomenclatura gramatical oficializada, preparado no sentido de garantir um modo de referência comum às entidades, e, assim, uma uniformização mínima de referências. Não se discutem, aqui, as vantagens e desvantagens da existência desse documento, ele apenas foi tomado como ponto de partida do exame pela conveniência de poder-se contar com um elenco de termos que, instituidamente, são vigentes no Brasil e podem testemunhar o que este estudo se propôs.

Como já indiquei ao configurar o propósito do trabalho, partindo desse núcleo comum de designações oficialmente vigentes no Brasil, foi possível chegar a uma amostra que mapeia conceptualmente posições relativas a língua e linguagem assumidas (e mantidas ou não), na história do pensamento ocidental sobre gramática, nossa fonte histórica natural.

NEVES, M. H. M. The legacy of Greek in the Brazilian grammatical terminology. Alfa, Araraquara, v.55, n.2, p.641-664, 2011.

- ABSTRACT: This study aims at investigating the existence of a Greek terminological legacy in the Brazilian grammatical organization, taking into account that the initial Greek grammar is the source of our grammar, through the Latin grammar, and that the field defined by it is a reference point for studying the evolution of Western thought about language. The theoretical and methodological approach is based on Historical Linguistics along the lines that guided the extensive research on the emergence of grammar in the West, which is the source of the information organized here (NEVES, 2005). The reflections focus on the examination of nomenclature, considering that it conceptually maps the set of positions assumed, and in general maintained, that deserve consideration. Among other things, the survey compared both Greek terms inherited in the continuous current of the grammatical thinking with Greek terms introduced later, and terms transliterated from the Greek with terms modeled on the Latin translation. In addition, there have been cases of names that were changed while the 
concept was kept and cases of concepts that were changed while the name was kept. Anyway, the examination of the nomenclature reveals the undeniable existence of a Greek legacy in the organization of the Portuguese grammar.

- KEYWORDS: Brazilian grammatical nomenclature. Alexandrian grammar. Western grammar.

\section{REFERÊNCIAS}

APOLONIUS DISCOLUS. Grammatici graeci. Aparato crítico e comentários de G. Uhlig e G. Schneider. Leipzig: Teubner, 1910.

BARBOSA, N. S. S. Interpretação da nomenclatura gramatical brasileira. Rio de Janeiro: CADES, 1962.

BEKKER, I. Anecdota graeca. Graz:Akademische Druck u.Verlagsanstalt, 1965. 3v. CHEDIAK, A. J. (Org.). A elaboração da Nomenclatura Gramatical Brasileira. Rio de Janeiro: CADES, 1960.

NEVES, M. H. M. A vertente grega da gramática tradicional. 2. ed. rev. São Paulo: Ed. da Unesp, 2005.

PRISCIANO. Editado por H. Keil. Grammatici latini. Hildesheim: G. Olms, 1961.

UHLIG, G. Dyonisii Thracis Ars Grammatica. Leipzig: Teubner, 1883.

\section{BIBLIOGRAFIA CONSULTADA}

SEXTUS EMPIRICUS. Works. Translated by R. G. Bury. Cambridge: Harvard University Press; London: William Heinemann, 1953-1959. 4v.

Recebido em março de 2011.

Aprovado em julho de 2011. 